\title{
ENGENHARIA DE MÉTODOS E APLICAÇÃO DE SEUS CONCEITOS EM UMA PIZZARIA. UM ESTUDO DE CASO NA PIZZARIA MONTEIRENSE
}

\author{
Beatriz Silva dos Passos Oliveira (UFCG) beattrizoliveira@hotmail.com \\ Gilson da Silva Vital (UFCG) gilsons628@gmail.com \\ Ingrid Rafaella Ferreira Duarte (UFCG) - ingridfduarte@ hotmail.com \\ Jefferson Teixeira de Souza (UFCG) jefferson97ufcg@gmail.com \\ Jose de Lima Henriques Junior (UFCG) jrhenrique01 @ gmail.com
}

\section{Resumo}

Este artigo tem como objetivo expor a aplicação de conceitos existentes dentre a engenharia de métodos direcionados para um conjunto de processos produtivos. O foco é a mostrar tempos de das operações do processo de produção através do uso da cronoanálise, mapeamento de fluxo e valores, nos possibilitando identificar quais processos contam com os maiores tempos de execução e consequentemente otimizar tal ou tais operações de forma concisa, viável e com eficácia, promovendo-se assim o controle de toda a produção e que todo o processo produtivo flua de forma que haja o atendimento da demanda sem que haja gargalos em tal produção.

Palavras-Chaves: Engenharia de métodos; Cronoanálise; Mapeamento de fluxo e valores.

\section{Introdução}

Nos dias de hoje as organizações buscam sempre o sucesso decorrente da boa satisfação de seus clientes. Para isso, se faz necessário a otimização de tais organizações que a partir disto já nos remete a filosofia Kaizen (tal filosofia que à grosso modo sugere a otimização contínua do processo produtivo com o menor custo), que consequentemente, implica na ascensão de tal organização e também no destaque em relação a outras organizações (ARAÚJO, 2006).

Segundo (FRANCO, 2018), otimizar é promover o fluxo de atividades de trabalhos, buscando e identificando atrasos e gargalos no âmbito produtivo, ou seja, desperdícios de recursos financeiros e tempo e erros de produção.

A engenharia de métodos é um ramo da engenharia que está diretamente destinada á melhoria e desenvolvimento de ferramentas e equipamentos presentes no processo produtivo. E assim, promovendo o método de execução de um determinado trabalho otimizado e mais eficiente alterando as máquinas e a formas que tais máquinas estão sendo manuseadas, leiaute, a movimentação de pessoas e materiais, dispositivos e ferramentas presentes ou prestes a ser implantadas no ambiente de produtivo, racionalização dos movimentos realizados e a medição 
de tempos das ações que são tomadas no processo produtivo (tempo de setup, por exemplo), (PEINADO e REIS, 2007) .

Diante disto, o presente trabalho irá expor um estudo de caso que iá abordar e expôr o uso de certas ferramentas (gráfico GBO, mapeamento de fluxo de valores, entre outros), e assim demostrando as otimizações realizadas na empresa aplicada, tornando-a mais eficiente e que tais aplicações sejam rentáveis para o negócio e que contribua para um melhor funcionamento da mesma.

\section{Desenvolvimento}

Com o intuito de expor todo o conceito necessário para o entendimento do artigo proposto, este tópico irá tratar de assuntos como arranjo físico, cronoanálise, estudo de tempos, capacidade de produção, balanceamento de linha, GBO, VSM (mapeamento de fluxos de valores) e o método $5 \mathrm{~W} 2 \mathrm{H}$.

\subsection{Arranjo físico}

Segundo (SLACK, CHAMBERS e JOHNSTON, 2009), um arranjo físico nada mais é que a distribuição física dos meios de produção em um determinado espaço. Ou seja, é como seus recursos transformadores são posicionados uns em relação aos outros e como as várias tarefas da operação serão alocadas a esses recursos transformadores. A maioria dos arranjos físicos, na prática, deriva de apenas quatro tipos básicos de arranjo físico:

a) Arranjo físico posicional é, de certa forma, uma contradição em termos, já que os recursos transformados não se movem entre os recursos transformadores. A razão para isso pode ser que ou o produto seja muito grande para ser movido de forma conveniente, ou pode ser (ou estar em um estado) muito delicado para ser movido.

b) Arranjo físico funcional ou arranjo físico por processo, se faz presente quando recursos ou processos similares são localizados juntos um do outro. A razão para isso é que pode ser conveniente para a operação mantê-los juntos, ou que dessa forma a utilização dos recursos transformadores seja beneficiada.

c) Arranjo físico celular aquele em que os recursos transformados, entrando na operação, são pré-selecionados (ou pré-selecionam-se a si próprios) para movimentar-se para uma parte específica da operação na qual todos os recursos transformadores necessários a atender às suas necessidades imediatas de processamento se encontram.

d) Arranjo físico por produto, envolve localizar os recursos produtivos transformadores inteiramente segundo a melhor conveniência do recurso que está sendo transformado. Cada produto, elemento de informação segue um roteiro predefinido no qual a sequência de atividades requerida coincide com a sequência na qual os processos 
foram arranjados fisicamente. Os recursos em transformação seguem um "fluxo" ao longo da "linha" de processos.

\subsection{Cronoanálise}

A cronoanálise é a abordagem mais comumente usada nos estudos de tempos. Ela é caracterizada pelo uso de cronometragem para determinar o tempo padrão de uma operação. Trata-se de uma técnica muito comum em ambientes industriais com tarefas repetitivas, sendo empregada para determinar metas de produção, estimar a capacidade produtiva e determinar custos de mão de obra (LIMA, 2016).

Segundo (DEWES, 2010), na área industrial, muitos são os aspectos passíveis de análise quando se fala em gestão de operações. Sob essa ótica, uma das ferramentas que pode ser utilizada objetivando um controle efetivo das atividades é a cronoanálise.

Para (BARNES, 1977) a leitura de cronometragem é definida por três métodos:

a) Leitura contínua, que o observador dá início à cronometragem a partir do primeiro elemento e mantém o cronômetro em movimento durante o período do estudo;

b) Leitura repetitiva, o analista lê o cronômetro, retorna a zero, e registra a leitura. Também observa os demais elementos, sempre anotando na folha de observações a cada leitura;

c) Leitura acumulada torna as subtrações desnecessárias, pois permite a leitura direta do tempo de cada elemento pelo uso de dois cronômetros. São dois cronômetros montados juntos que com um mecanismo de alavanca quando um é iniciado o segundo para automaticamente e vice-versa.

Segundo Veloso et al. (2012), essa cronometragem é feita após a divisão da operação em elementos para se obter um tempo mais preciso.

Com a intenção de validar as amostras de tempos cronometrados, Peinado e Graeml (2007) apresentaram a Eq. (1), para determinar o número de ciclos a serem cronometrados:

$$
n=\left(\frac{z x R}{E r x d_{z} x \mathrm{x}}\right)^{2}
$$

$\mathrm{Na}$ eq.(1), z é considerado o coeficiente da distribuição normal para uma probabilidade determinada, $\mathrm{R}$ é a amplitude da amostra, Er o erro relativo da medida, d2 indica o coeficiente em face do número de cronometragens feitas preliminarmente e por, $\overline{\mathrm{X}}$ que é média da amostra, que a partir dessas variáveis se dá o n, que é o número de ciclos a serem 
cronometrados. Assim, o tempo de ciclo de uma operação é o tempo cronometrado (TC) ou tempo real, considerando uma eficiência de $100 \%$.

\subsection{Estudo de tempos, movimentos e métodos}

De acordo com (NEGREIROS e LIMA, 2011) a engenharia de métodos objetiva estabelecer padrões, que por meio de um estudo de tempos de um trabalho de forma sistemática é capaz de determinar um método mais prático e eficiente para realização de uma atividade. Para isso utiliza o registro e a análise de determinada atividade, visando encontrar o método para realizar essa atividade de forma que aumente a produtividade.

Segundo (BARNES, 1977) a união dos estudos de tempos e movimentos foi introduzida por Taylor que determinou os tempos padrões de um processo e pelo casal Gilbreth que desenvolveu um estudo para melhoria de métodos de trabalhos, com o objetivo de alcançar um método que mais aproximasse o ideal da forma prática. Assim, por meio de análises, este estudo propôs o melhor método para executar uma tarefa, determinando o tempo que uma pessoa treinada levaria para cumprir tal atividade e assim padronizando esse tempo, visando a redução de custos e a eliminação de movimentos desnecessários.

\subsubsection{Tempo normal}

De acordo com (BARNES, 1977), o tempo que um operador leva para realizar uma atividade, no seu ritmo normal, considerando suas limitações e habilidades, é conhecido como tempo normal.

Segundo (PEINADO e REIS, 2007), quando se determina o tempo de execução uma operação é preciso levar em conta a velocidade com que o operador está realizando a operação. Para tornar o tempo utilizável para todos os trabalhadores, a medida da velocidade, que é expressa como uma taxa de desempenho que reflete o nível de esforço do operador observado, deve também ser incluída para "normalizar" o trabalho. O tempo normal se dá pela eq.(2) a seguir:

$$
T N=T C x V
$$

Onde teremos TN como tempo normal, TC como tempo normal e V velocidade do operador.

\subsubsection{Tempo padrão}

Segundo (PEINADO e REIS, 2007) afere que, a partir do tempo normal calculado, será preciso levar em consideração que não é possível um operário trabalhar o dia inteiro, sem nenhuma interrupção, tanto por necessidades pessoais, como por motivos alheios à sua vontade. E assim, o tempo padrão poderá ser calculado multiplicando o tempo normal por um fator de tolerância para compensar o período que o trabalhador, efetivamente, não trabalha. $\mathrm{O}$ cálculo é feito utilizando-se a eq.(3).

$$
T P=T N \times F T
$$


Onde, TP será o tempo padrão, TN o tempo cronometrado e FT o fator de tolerância.

\subsubsection{Fator de tolerância}

Para (MARTINS e LAUGENI, 2006), a fadiga é dependente das condições do trabalho e para um regime de trabalho de oito horas, é aceitável uma tolerância de 10 a 25 minutos por turno. É importante observar que esta tolerância pode variar de indivíduo para indivíduo, de país para país, e de acordo com a natureza e ambiente de trabalho (PEINADO e REIS, 2007).

A Eq. (4) determina o fator de tolerância:

$$
F T=\frac{1}{(1-P)}
$$

Onde FT é o fator de tolerância e $\mathrm{P}$ o tempo permissivo.

\subsection{Capacidade produtiva}

Segundo (PORTAL, 2015), a palavra capacidade está ligada a ideia de volume máximo de alguma coisa, algum produto, algum serviço, etc. A capacidade produtiva de uma empresa pode ser definida quando se conhece o tempo padrão das operações de um processo produtivo. (SLACK, CHAMBERS e JOHNSTON, 2009) por sua vez, diz que a capacidade produtiva que uma empresa possui representa o seu potencial de produção, bem como o volume ideal de produtos ou serviços a ser realizado pela mesma. Para tanto, vale ressaltar que a capacidade produtiva permite maximizar a lucratividade e minimizar os custos de produção.

De acordo com (REIS, 2018), existem diferentes formas de classificar e analisar a capacidade produtiva de uma empresa. As principais são:
a) Capacidade produtiva instalada;
b) Capacidade produtiva disponível;
c) Capacidade produtiva efetiva;
d) Capacidade produtiva realizada.

\subsubsection{Capacidade produtiva instalada}

Corresponde a capacidade produtiva total que a empresa tem, de acordo com sua infraestrutura. A capacidade instalada considera o potencial produtivo máximo da empresa, onde todos os fatores de produção (máquinas, insumos, matéria-prima, funcionários) estariam funcionando de forma plena - sem a ocorrência de interrupções, perdas, faltas, ou demais imprevistos. É um indicador hipotético, que serve de referencial para a tomada de decisões estratégicas (REIS, 2018).

\subsubsection{Capacidade produtiva disponível}


Informa qual é a capacidade produtiva disponível para a empresa em um exato momento. Ou seja, o cálculo leva em conta apenas os ativos e insumos que podem entrar em funcionamento efetivamente naquele instante. A capacidade disponível também não considerada as perdas, faltas ou paradas por qualquer motivo (REIS, 2018).

\subsubsection{Capacidade produtiva}

Representa o nível de produção que a empresa efetivamente consegue ter. É baseada em cima da capacidade disponível, mas com uma provisão de perdas, faltas, paradas por manutenção e demais interrupções planejadas durante a produção. Por serem fatores previsíveis e controlados, é possível inclui-los cálculo de capacidade efetiva (REIS, 2018).

\subsubsection{Capacidade produtiva efetiva}

Corresponde à capacidade efetiva, mas considerando também as perdas e paradas que não são planejadas. Entram nesse cálculo eventos como como interrupção de energia, falta de matérias primas, ausência de funcionários, danos na infraestrutura, entre outros. Como são fatores imprevisíveis, a capacidade realizada é calculada por uma estimativa - que leva em conta a probabilidade desses eventos acontecerem e o histórico da empresa (REIS, 2018).

\subsection{Balanceamento de linha}

O Balanceamento de Linhas trata de nivelar os seus níveis de produção, com relação aos tempos, uma linha de produção ou de montagem, dando a mesma carga de trabalho às pessoas ou máquinas. O balanceamento anula os "gargalos" de produção proporcionando o máximo de produtividade e eficiência, eliminando as "esperas" e mantendo o ritmo de trabalho do conjunto (GESTÃO, 2013).

Para (GESTÃO, 2013), deve-se considerar os fatores de infraestrutura, métodos operacionais e recursos humanos envolvidos, também deve-se levar em conta os tipos de linha para realizar o balanceamento, que podem ser balanceamento de linhas de produção e balanceamento de linhas de montagem.

De acordo com (TUBINO, 2007), balanceamento é como um conjunto de atividades que serão executadas de forma a garantir um tempo aproximadamente igual entre os postos de trabalho. Este tempo é definido como Takt Time ou tempo meta.

O "Takt Time" corresponde ao ritmo de produção necessário para atender a demanda, ou seja, o tempo de produção que tem disponível pelo número de unidades a serem produzidas em função da demanda. O takt time pode ser calculado pela seguinte equação:

$$
T T=\frac{\text { Tempo disponivel }}{\text { Demanda }}
$$


Se o tempo de ciclo for maior que o Takt Time, não é possível produzir conforme a demanda do cliente, ocorrendo atrasos no sistema produtivo. Na possibilidade de ocorrer o inverso, o Takt Time for maior que o tempo de ciclo ocorrerá o excesso de produção acarretando no conceito de MUDA (desperdício). O ideal é que o tempo de ciclo e o Takt Time estejam com valores próximos (PRODUÇÃO, 2015).

\subsection{Gráfico de balanceamento de operadores (GBO)}

É usado para determinar quais as tarefas que cada operador deve realizar em seu posto de trabalho. As atividades são divididas em operações que agregam valor e operações que não agregam valor ao produto. Segundo (GOMES, OLIVEIRA, et al., 2008) a linha do takt time está presente como referência para a distribuição de tarefas e balanceamento o que permite uma comparação com o cycle time.

Para construir o GBO, o primeiro passo é cronometrar cada elemento de trabalho separadamente de toda a sequência de trabalho executada pelo operador.

\subsection{Mapeamento de fluxo de valores (VSM)}

Para (ROTHER e SHOOK, 2003), um fluxo de valor é toda ação (agregando valor ou não) necessária para trazer um produto por todos os fluxos essenciais a cada produto: o fluxo de produção desde a matéria-prima até os braços do consumidor, e o fluxo do projeto do produto, da concepção até o lançamento, ou seja, é uma ferramenta que ajuda a enxergar e entender o fluxo de material e de informação na medida em que o produto segue o fluxo de valor.

\section{8. $5 w 2 h$}

O 5W2H é um checklist de determinadas atividades que precisam ser desenvolvidas com o máximo de clareza possível por parte dos colaboradores da empresa. Ele funciona como um mapeamento destas atividades, onde ficará estabelecido o que será feito, quem fará o quê, em qual período de tempo, em qual área da empresa e todos os motivos pelos quais esta atividade deve ser feita (PERIARD, 2009).

O nome desta ferramenta foi assim estabelecido por juntar as primeiras letras dos nomes (em inglês) das diretrizes utilizadas neste processo:
a) What - O que será feito (etapas);
b) Why - Por que será feito (justificativa);
c) Where - Onde será feito (local);
d) When - Quando será feito (tempo);
e) Who - Por quem será feito (responsabilidade);
f) How - Como será feito (método);
g) How much - Quanto custará fazer (custo). 
Para (PERIARD, 2009), antes de utilizar o 5W2H é preciso que você estabeleça uma estratégia de ação para identificação e proposição de soluções de determinados problemas que queira sanar.

\section{Procedimento metodológico}

Através de uma pesquisa quantitativa e qualitativa, tentou-se extrair todos os dados necessários para aplicar os métodos corretos e achar os gargalos presentes nas operações, com o intuito de minimiza-los ao máximo. Assim foram feitas 4 (quatro) visitas técnicas a empresa para coletar dados como tempo de cada etapa da operação, medidas do ambiente para o esboço de uma planta baixa, etc.

Dados como localização da empresa, demanda, funcionamento de cada etapa da produção, foram obtidos através de entrevista com o proprietário da empresa, por exemplo, eficiência do forno. Já dados qualitativos como tempos cronometrados, além da entrevista citada a cima, fez-se necessário o uso de ferramentas que facilitasse a obtenção dos dados, como o cronômetro que foi indispensável.

Tratando de representação gráfica, utilizou-se o AutoCAD para criação do layout da empresa com todas as características necessárias para o estudo, Microsoft Office Word para o fluxograma vertical para cada etapa da produção, Microsoft Office Excel que possibilitou a aplicação do takt time e cycle time para ilustração do gráfico GBO e por fim, o software Lucidchart na representação do VSM (Mapeamento de Fluxo de Valor).

\section{Análise de resultados}

A empresa em que foi tomada como objeto de estudo, está localizada no Cariri paraibano, mais precisamente na cidade de Monteiro, Paraíba. A mesma é uma empresa do ramo alimentício (pizzaria) que em sua estrutura organizacional conta com sete funcionários, sendo um gerente, um pizzaiolo, dois entregadores e três atendentes que são organizados para realizar os processos de acordo com o VSM presente na Figura 1.

A mesma conta com um arranjo físico funcional (onde se há os setores definidos em que a matéria-prima será transformada de acordo com a sua finalidade e que para um melhor entendimento, ver Figura 2) e conta com um sistema de pedidos de acordo com o empuxe do cliente final. E sem contar que a mesma conta com uma demanda mensal de aproximadamente 816 pizzas, mas tendo como carga-horária, 6 horas diárias com dias de funcionamento de terça a domingo.

Figura 1 - Mapeamento de Fluxo de Valor 


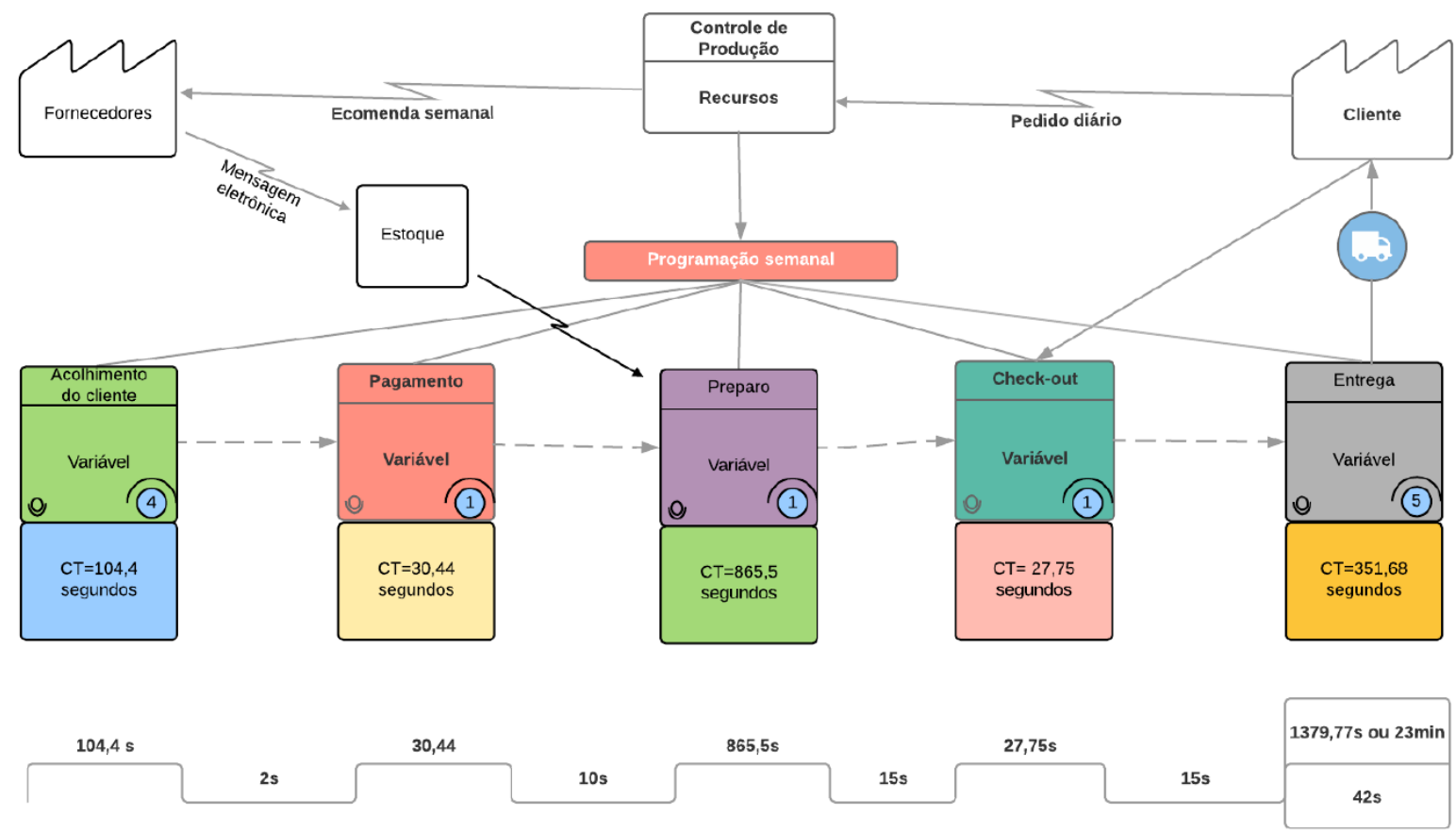

Fonte: autoria própria (2018)

Figura 2 - Planta baixa da Pizzaria Monteirense 


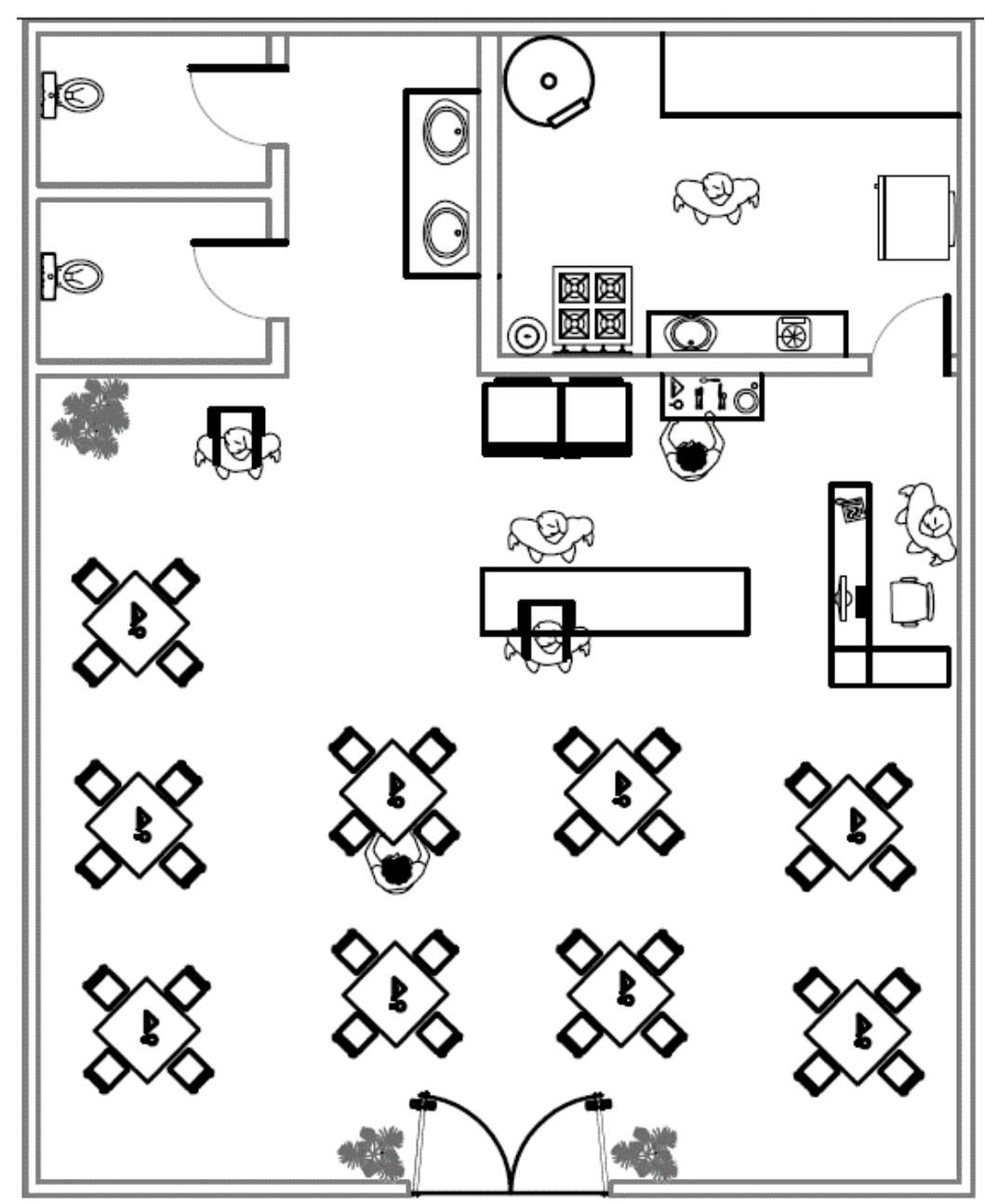

Fonte: autoria própria (2018)

De acordo com o que já foi exposto na fundamentação teórica do presente trabalho, se faz o uso da demonstração dos dados recolhidos previamente ao estudo, em seguida a aplicação de ferramentas presentes na engenharia de métodos e em seguida a exposição das otimizações que ocorreram com a aplicação de tais ferramentas.

Como foram realizadas as observações e consequentemente a definição das etapas de todo o processo produtivo (Acolhimento do cliente, Pagamento, Preparo, Check-out e Entrega), foise formulado o fluxograma vertical de cada uma das etapas e nele há a indicação do tempo padrão (tendo como base as equações 1,2 e 3 , tendo seus resultados finais em segundos) de cada um dos processos (ver Tabelas 1 á 5). 
Figura 3 - Fluxograma vertical do acolhimento ao cliente

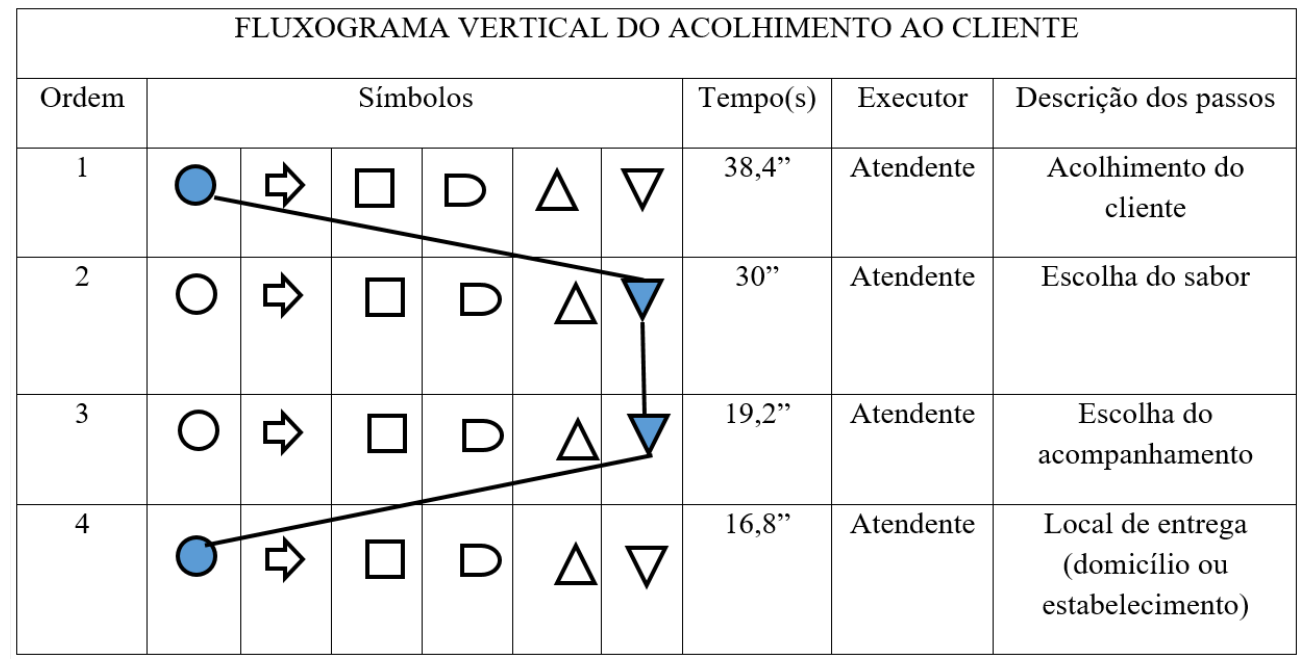

Fonte: autoria própria (2018)

Figura 4 - Fluxograma vertical do pagamento

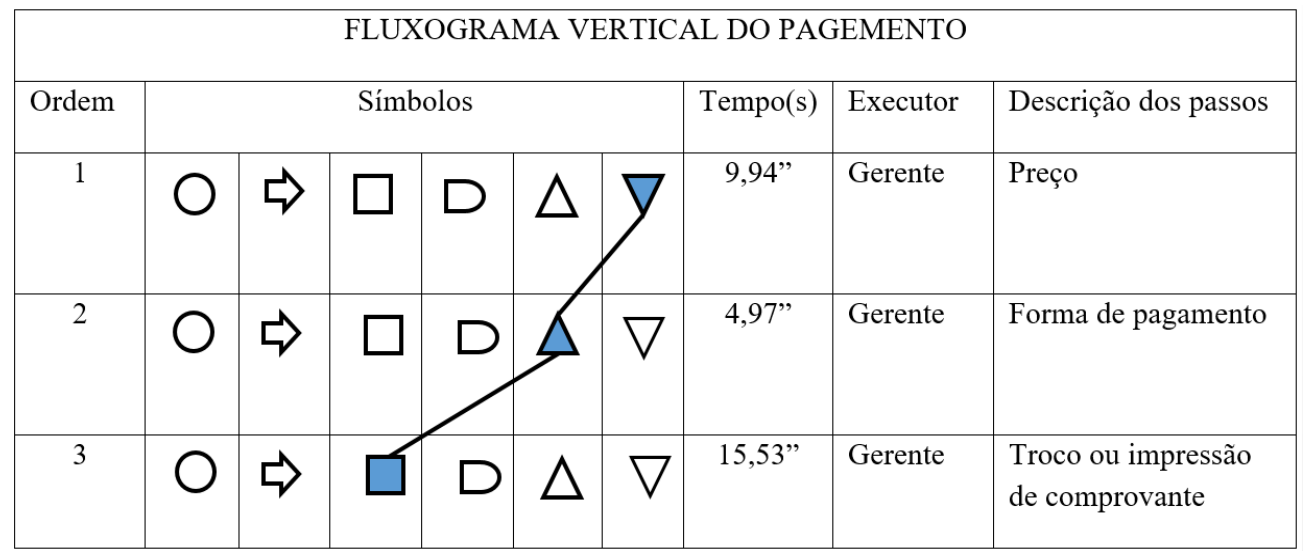

Fonte: autoria própria (2018) 
Figura 5 - Fluxograma vertical do preparo

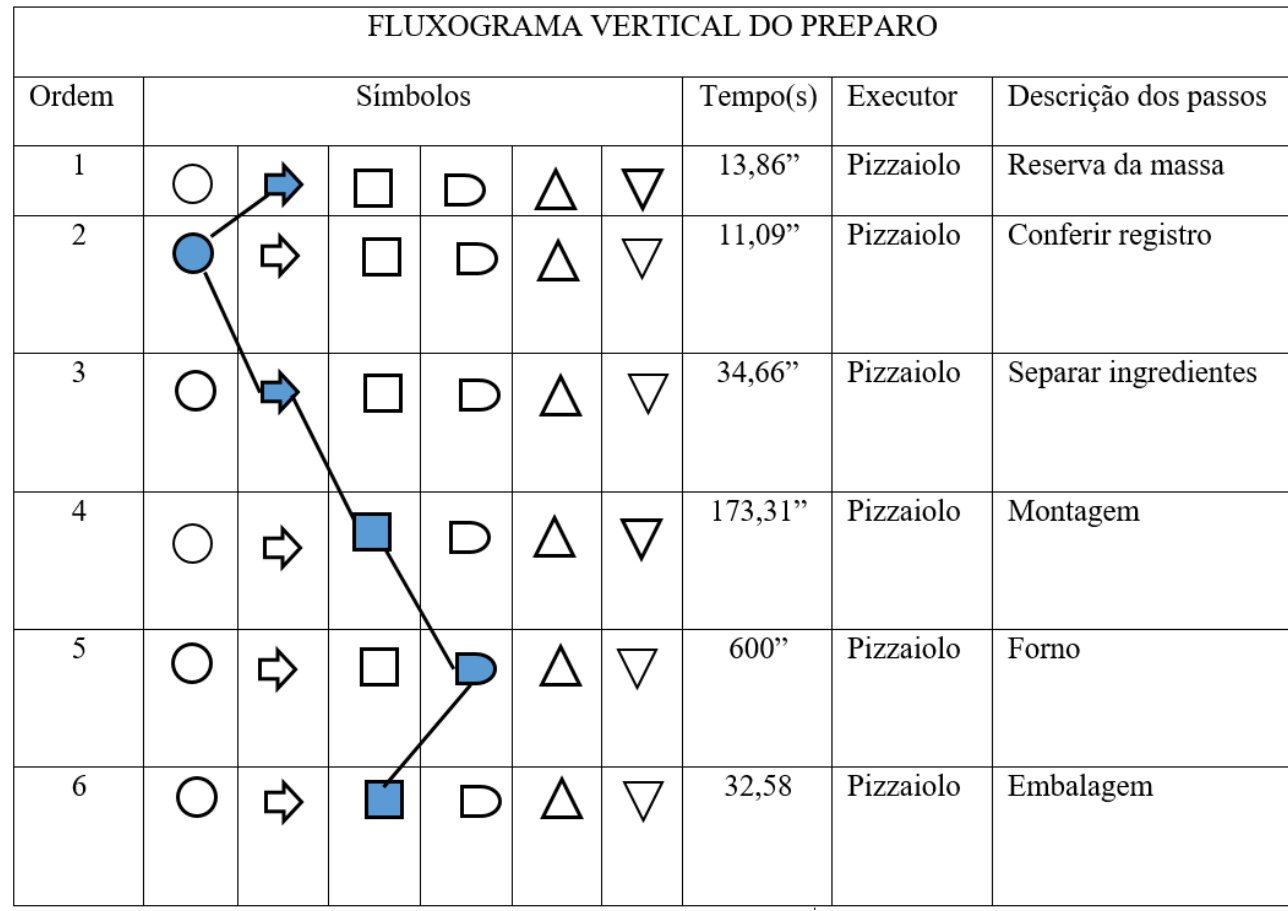

Fonte: autoria própria (2018)

Figura 6 - Fluxograma vertical do Check-out

\begin{tabular}{|c|c|c|c|c|c|c|c|l|l|}
\hline \multicolumn{7}{|c|}{ SLUXOGRAMA VERTICAL DO CHECK-OUT } \\
\hline Ordem & \multicolumn{7}{|c|}{} \\
\hline 1 & $\bigcirc$ & $\Delta$ & $\square$ & $\square$ & $\triangle$ & $\nabla$ & $27,75 ”$ & Atendente & $\begin{array}{l}\text { Vistoria do pedido } \\
\text { referente ao registro }\end{array}$ \\
\hline
\end{tabular}

Fonte: autoria própria (2018)

Figura 7 - Fluxograma vertical da entrega

\begin{tabular}{|c|c|c|c|c|c|c|c|l|l|}
\hline \multicolumn{7}{|c|}{ SLUXOGbolos } & Tempo(s) & Executor & Descrição dos passos \\
\hline Ordem & \multicolumn{7}{|c|}{} \\
\hline 1 & $\bigcirc$ & $\Rightarrow$ & $\square$ & $\square$ & $\triangle$ & $\nabla$ & $11,77 ”$ & Atendente & Auxílio ao entregador \\
\hline 2 & $\bigcirc$ & $\Leftrightarrow$ & $\square$ & $\square$ & $\triangle$ & $\nabla$ & $339,91 ”$ & Entregador & Entrega do pedido \\
\hline
\end{tabular}

Fonte: autoria própria (2018)

Portando tais dados, foi-se calculado o cycle time (soma dos tempos padrões) de cada operação para que assim possamos aplicar tais resultados ao cálculo do takt time (que está interligado com o cálculo do Fator de Tolerância, ver equação 4) ,e com isso, formarmos o 
gráfico GBO da situação em estudo do processo produtivo em questão que irá nos mostrar qual das etapas iremos otimizar. E assim temos:

Figura 8 - Cycle Times das operações

\begin{tabular}{|l|l|}
\hline \multicolumn{2}{|c|}{ Cycle Times das operações } \\
\hline$C T_{1}$ & 104,4 " \\
\hline$C T_{2}$ & $30,44 "$ \\
\hline$C T_{3}$ & $865,5^{“}$ \\
\hline$C T_{4}$ & $27,75^{“}$ \\
\hline$C T_{5}$ & $351,68^{\prime \prime}$ \\
\hline$C T_{t}$ & 1979,77 segundos \\
\hline
\end{tabular}

Fonte: autoria própria (2018)

De acordo com a equação do fator de tolerância, obtivemos o seguinte resultado:

$$
\underline{\mathrm{Ft}}=1,09
$$

Relacionando o tempo de expediente com o fator de tolerância, temos o tempo disponível e aplicando a equação do Takt Time, temos:

$$
\mathrm{Tt}=635,28 \mathrm{seg} / \mathrm{unid}
$$

E com isso possibilitando criarmos o gráfico GBO (ver Gráfico 1):

Gráfico 1 - Gráfico GBO da situação atual da empresa

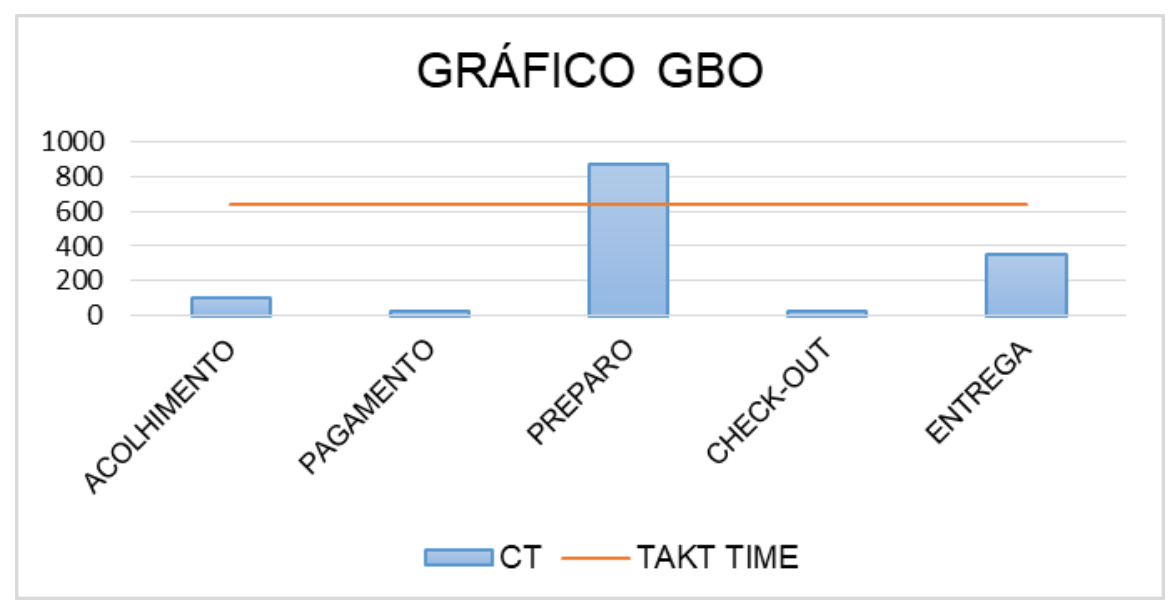

Fonte: autoria própria (2018)

Com a exposição dos tempos, cálculo da Takt Time e montagem do gráfico GBO, é notório a etapa que precisa ser otimizada, ou seja, a etapa de maior duração que o tempo da etapa de cozimento. Dentre esta etapa investigou-se qual seria a operação de maior tempo de execução (neste caso, a operação de cozimento). Para identificarmos e acharmos uma melhor solução 
que contribuísse para a otimização de tal operação utilizou-se o $5 \mathrm{~W} 2 \mathrm{H}$, e assim tendo a seguinte descrição:

a) O que: Tempo de forno elevado / Implementação de um forno mais eficiente

b) Por que: Ineficiência do forno / Principal gargalo da etapa e apresenta um maior tempo em toda a produção

c) Onde: Cozinha

d) Quando: Na etapa de preparo

e) Quem: Pizzaiolo

f) Como: Rearranjo do layout da cozinha e aquisição de um novo forno mais eficiente.

g) Quanto: aproximadamente 950 reais (15 pizzas por hora).

Com aplicação de tal solução (o novo forno), houve consequentemente a mudança do tempo de preparo e assim obtendo um novo gráfico GBO que agora otimizado e condizente com a capacidade da empresa e consequentemente com a demanda a ser cumprida (ver Gráfico 2).

Gráfico 2 - GBO pós aplicação de otimização

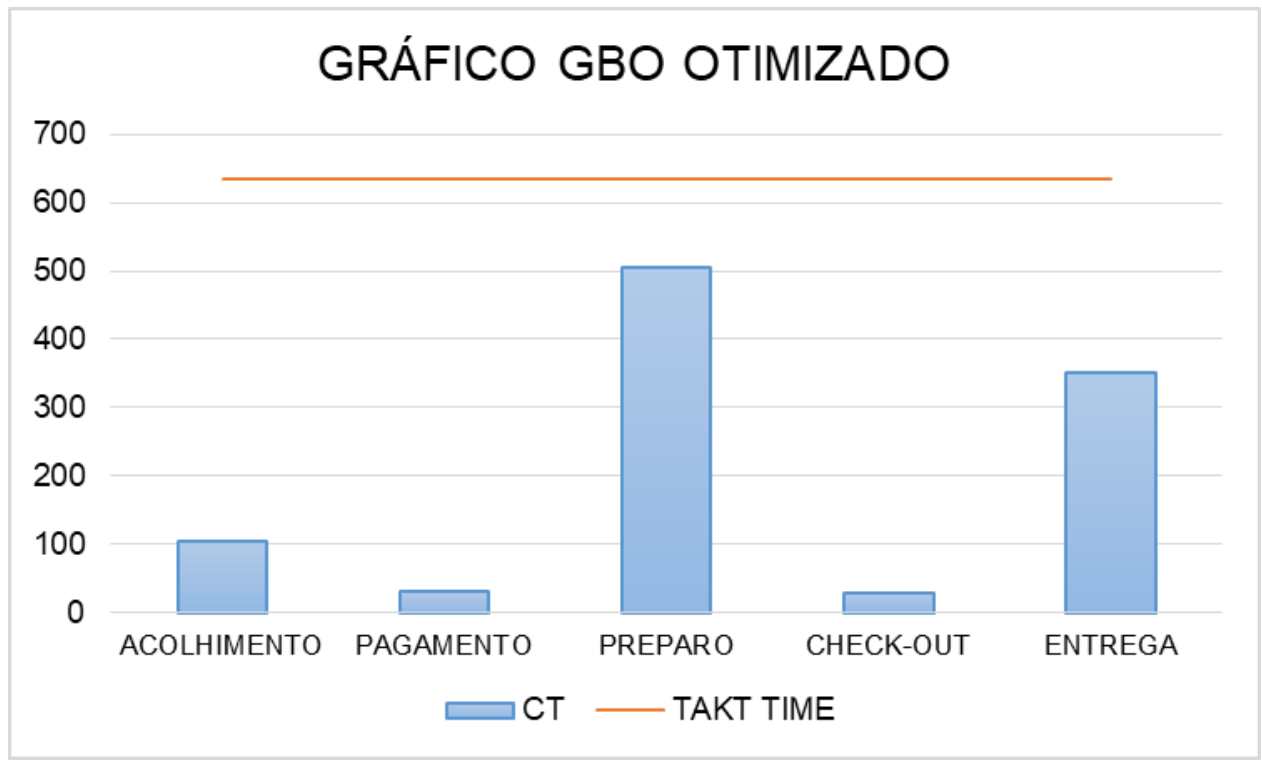

Fonte: autoria própria (2018)

E assim, mostrando que de acordo com o plano de ação que foi estudado e aplicado, teve-se melhoras nos resultados de tempos no que diz respeito ao processamento na empresa em questão.

\section{Considerações finais}


Com a busca constante pela otimização de processos para que haja a fluidez dos processos produtivos realizados em um determinado local, se fez necessário a aplicação de determinadas ferramentas contidas dentre o estudo da engenharia de métodos (VSM, gráfico GBO, estudo de tempos e movimentos, entre outros).

Contudo, referente ao apresentação teórica tudo que se diz respeito aos dados adquiridos decorrente a pesquisa de tal trabalho, obtivemos e foi-se atingido o objetivo de tal trabalho que seria observar, medir e aplicar o estudo de tempos e métodos a ele agregar ferramentas de suma importância para tal situação. E assim, obtendo a otimização de uma empresa, diminuindo custos, tempo processamento e consequentemente a satisfação do consumidor final.

\section{Referências}

ABDULLAH, F. Lean Manufacturing tools and techniques in the process industry with a focus on , Pittsburgh, 2003.

ARAÚJO, L. C. G. de. Organizações, Sistemas e Métodos e as novas tecnologias de gestão organizacional. Vol. 2 - $2^{\mathrm{a}}$ ed. - São Paulo: Atlas, 2006.

BARNES, R. Estudo de movimentos e de tempos: projeto e medida do trabalho. $3^{\circ}$. ed. São Paulo: Edgard Bucher, 1977. Acesso em: 07 Dezembro 2018.

DEWES, L. F. Setor de Cronoanálise: Estudo de caso em uma empresa de estamparia do vale dos sinos. Universidade Feevale. Novo Hhamburgo. 2010.

FRANCO, F. Helioprint, 2018. Disponivel em: <helioprint.com.br/blog/>. Acesso em: 07 Dezembro 2018.

GESTÃO, M. Linhas de Produção. Mais Gestão, 2013. Disponivel em:

<http://www.gestaodeproducao.com.br/servicos/balanceamento/balanceamento-de-linhas>. Acesso em: 07 Desembro 2018.

GOMES, J. E. et al. Balanceamento de Linha de Montagem na Industria Automotiva - Um Estudo de Caso. ENEGEP, Rio de Janeira, p. 1-13, 2008.

LIMA, R. Introdução à Cronoanálise com Exemplo. Aprendendo Gestão, 2016. Disponivel em: <http://aprendendogestao.com.br/introducao-a-cronoanalise/>. Acesso em: 07 Desembro 2018.

MARTINS, P.; LAUGENI, F. Administração da Produção. $2^{\circ}$. ed. São Paulo: Saraiva , 2006.

NEGREIROS, R. F. D.; LIMA, R. N. Projeto de engenharia de métodos numa fábrica de sorvetes. Seprone - Simpósio de Engenharia de Produção da Região Nordeste, v. 01, 2011. 
PEINADO, J.; REIS, A. Administração da Produção. Curitiba: [s.n.], 2007.

PERIARD, G. O que é o 5W2H e como ele é utilizado. Sobre Administração, 2009.

Disponivel em: <http://www.sobreadministracao.com/o-que-e-o-5w2h-e-como-ele-eutilizado/> . Acesso em: 07 Dezembro 2018.

PORTAL, C. Capacidade de Produção. Portal Educação, 2015. Disponivel em:

$<$ https://www.portaleducacao.com.br/conteudo/artigos/administracao/capacidade-deproducao/21944>. Acesso em: 07 Dez 2018.

PRODUÇÃO, E. D. Cálculo do Takt Time e Avaliações. Engenharia de Produção, 2015. Disponivel em: <http://engenhariadeproducaoindustrial.blogspot.com/2015/04/calculo-dotakt-time-e-avaliacoes.html>. Acesso em: 07 Dezembro 2018.

REIS, T. O que é capacidade produtiva e qual é a sua importância para a empresa. Suno Research, 2018. Disponivel em: <https://www.sunoresearch.com.br/artigos/capacidadeprodutiva/> . Acesso em: 07 Dezembro 2018.

ROTHER, M.; SHOOK, J. Aprendendo a Enxergar. São Paulo: [s.n.], 2003.

SLACK, N.; CHAMBERS, S.; JOHNSTON, R. Administração da Produção. $3^{\circ}$. ed. [S.1.]: Atlas, 2009.

TAPPING, D.; LUYSTER, T.; SHUKER, T. alue Stream Management, New York, 2002. $162 \mathrm{p}$.

TUBINO, D. F. Planejamento e controle da produção: Teoria e prática. São Paulo: Atlas, 2007.

VELOSO, R. Estudo de tempos aplicado a um serviço de revisão geral de motocicletas na cidade de redenção-PA. Encontro Nacional de Engenharia de Produção, Bento Gonçalves , Out 2012. 